العوامل المؤثرة في الكفاءة الإنتاجية ومعدل التوأمية للموسم الأول للماعز الثامي (الامشقي) في سوريا

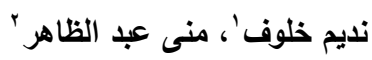

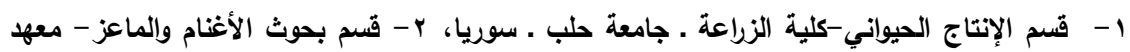

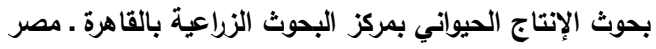

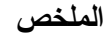

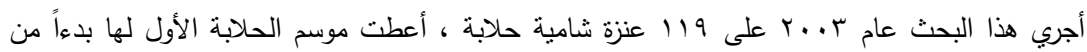

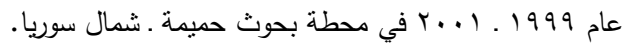

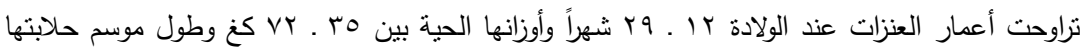

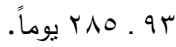

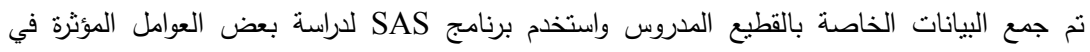

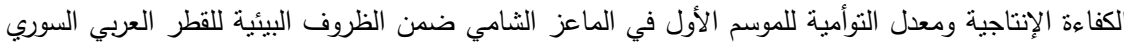
بالإضافة إلى تقدير معامل الانحدار لصفة التوأمية على العمر والوزن الحي للعنزة وكذلك معامل الانحدار

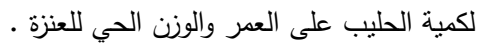

وبينت النتائج المتحصل عليها :

• إن منتوسط إنتاج الحليب لقطيع الماعز الثامي المدروس بلغ كغ /بالموسم وبمعدل نوأمبه 1.01.

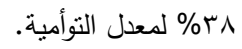

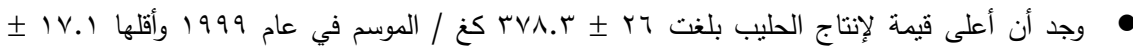

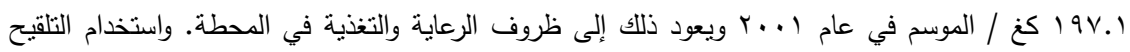
المبكر للعنزات في هذا العام.

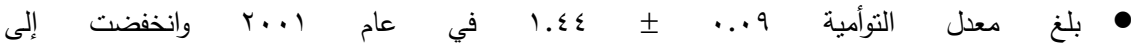
ب ا.. 土 هץ. P > معنوية قيمة معامل الانحدار لصفة التوأمية على العمر والوزن الحي للعنزة عند التلقيح عند مسنتى P ) (0.05 ). وكذللك المعنوية العالية لقيمة معامل الانحدار لكمية الحليب على العمر والوزن الحي عند التلقيح $\cdot(<0.01$

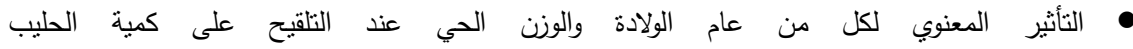
( P<0.05) )، بينما تأثثر العمر عند التلقيح فكان غير معنوياً على نفس الصفة. بلغت قيمة معامل القيمة التوريثية لصفة إنتاج الحليب ء ... 
يربى الماعز الثامي في جميع محافظات القطر العربي السوري ، ويتميز بمقدرته على تتاول الأعلاف

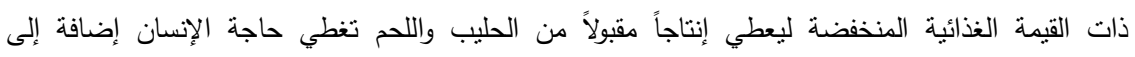
المنتجات الأخرى وخاصة في الدول النامية.

ويحتل الماعز الثامي في سورية خاصة والدول العربية عامة المركز الثالث بعد الأغنام والأبقار من حيث

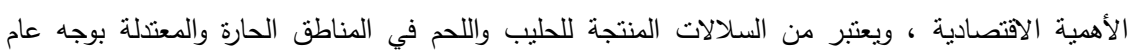
والثرق (Devendra and Nazawa, C. 1976,1983, FAO,1994, Contentinous. 1989)

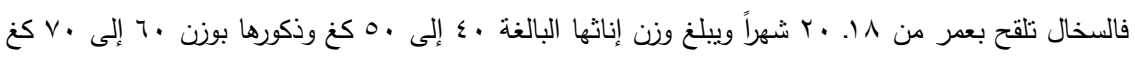

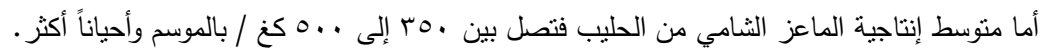

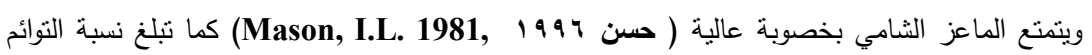

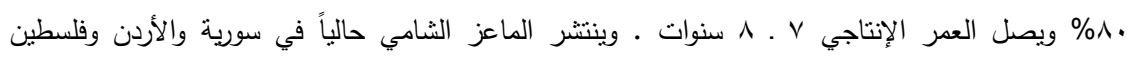

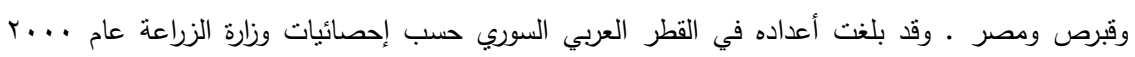

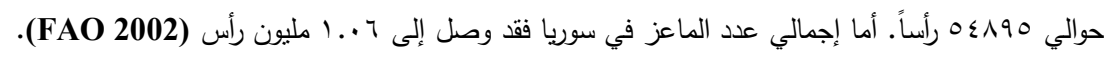
ومن الملاحظ أن أعداده ما زالت قليلة ومحدودة في القطر العربي السوري إضافة إلى أن النتائج المنشورة حول إنتاجية الماعز الثامي في القطر العربي السوري منباينة سواء في إنتاج الحليب أو في أوزان المواليد وتطور نموها ( حسن 1997 ، أبي صعب . . . . ) . وربما يكون سببه عائداً إلى اختلاف نسبة التوائم ومستوى التغذية وطريقة التربية والعمر عند الفطام للمواليد وكفاءة العنزة الإنتاجية من الحليب.

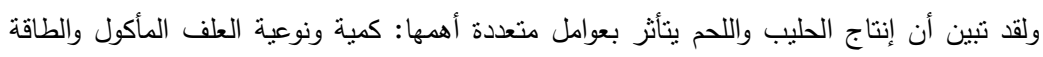
الناتجة عنه ، وعمر العنزة وطول موسم الحلابة وشهر الولادة ووزن العنزة قبل وبعد الولادة ونوع الولادة إضافة

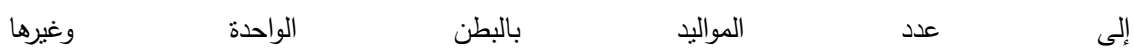
Abdel-Monem, 1986، حسن 1999) وقد أثنتت كثير من الأبحاث المجراة على الماعز الثامي

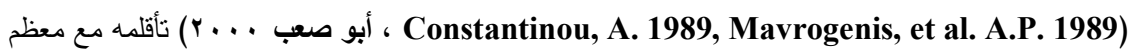
البيئات المناخية الحارة والرطبة والمعتلالة ، وبمقدرته الوراثية الجيدة وإمكانية تحسين إنتاجيته من الحليب واللحم

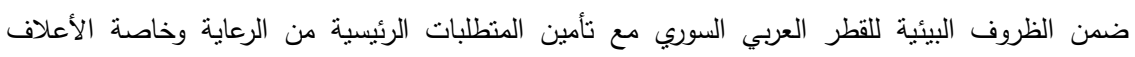
الخضراء. من هذا المنطلق اهتمت الدولة بتربية الماعز الثامي ، وللحفاظ عليه أنشأت في سورية محطات

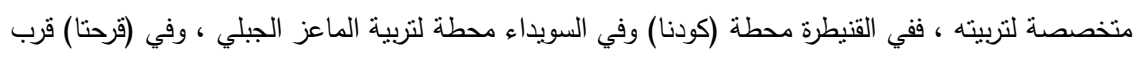
دمشق محطة لتربية الماعز الثامي وفي (أزرع) بدرعا، (والحميمة) قرب حلب لتحسين الماعز الثامي وهنالك دراسة لإنشاء محطة لتربية الماعز الثامي في ادلب مما يدل على اهتمام الدولة بهذا الحيوان.

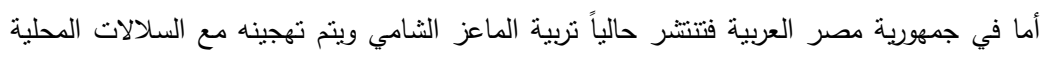
كالزرايبي والبلدي (في محطة سخا بكفر الثيخ والنوبارية والسرو وبرج العرب بالإسكندرية) بهدف نشر صفاته 


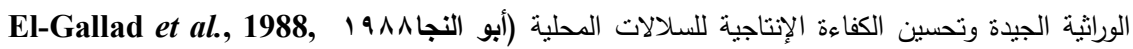
.(Mabrouk et al., 1997, Mavrogenis et al., 1984, Said, M. M. 1983

هدف البحث Objective of Research: • دراسة بعض العوامل المؤثرة على الكفاءة الإنتاجية ومعدل التوأمية للموسم الأول كالعمر والوزن الحي عند التلقيح وتغير إنتاج الحليب ومعدل التوأمية خلال سنوات الدراسة ضمن الظروف البيئية في سوريا. . تقدير قيمة معامل الاتحدار لصفة التوأمية على العمر والوزن الحي للعنزة. . تقدير قيمة معامل الانحدار لصفة كمية الحليب على العمر والوزن الحي للعنزة. . تقدير معامل القيمة التوريثية لصفة إنتاج الحليب. • بدء تشكيل قطيع نواة من الماعز الثامي بحوث حميمة. ونشر أنسالها في محطات الدولة والدول العربية المجاورة.

: Materials and Methods مواد وطرائق البحث ـ تم استخدام السجلات الإنتاجية ل 119 عنزة من قطيع الماعز الثامي المدروس بدءاً من عام 1999 ( وحتى . r...

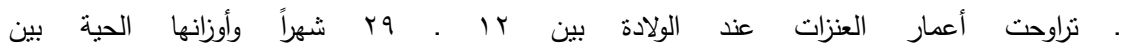

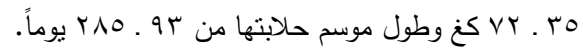

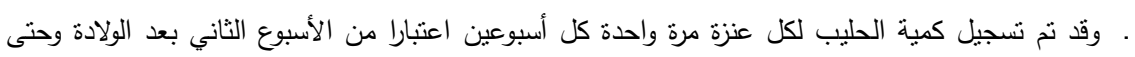
نهاية موسم الحليب. حيث تحلب العنزات يوميا مرتين صباحا ومساء.

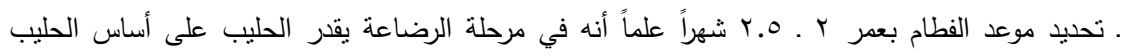

$$
\text { ـ أما بعد الفطام فيقدر إنتاج الحليب اليومي من الحلبة الصباحية والمسائية معاً. }
$$

التحاليل الإحصائية:

. تم تحيث نم تقدير كل من المتوسط XAS والخطأ القياسي SE ومعامل

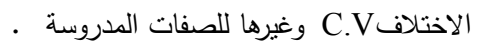
• حساب معامل الانحدار لصفة كمية الحليب ومعدل التوأمبة في الموسم الأول على العمر والوزن الحي عند التلقيح من المعادلة الخطية التالية: $Y=a+b_{1} x_{1}+b_{2} x_{2}$ حيث أن : ثابت القياس للصفة المدروسة ويعبر عن الجزء المقطوع من محور الصادات ( العينات ).

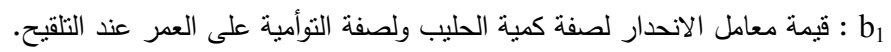
b2 : : قيمة معامل الانحدار لصفة كمية الحليب ولصفة التوأمية على الوزن عند التلقيح. • العمر عند التلقيح / شهراًا : X 


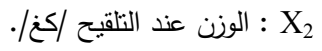

$$
\begin{aligned}
& \text { ـ استخدام تحليل التباين لدراسة تأثير العوامل المدروسة ( غير الوراثية ) على صفة كمية الحليب ومعدل التوأمية }
\end{aligned}
$$

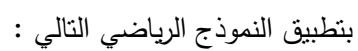

$$
\begin{aligned}
& \mathrm{Y}=\mu+\mathrm{K}_{\mathrm{i}}+\mathrm{A}_{\mathrm{j}}+\mathrm{W}_{\mathrm{k}}+\mathrm{e}_{\mathrm{ijk}} \\
& \text { حيث } \mu \text { : المتوسط العام Over all Mean } \\
& \text {. The effect due to year of kidding التأثثر العائد لسنة الولادة : Kن } \\
& \text {. The effect of age at mating تأثير عمر العنزة عند النقاثيح : : } \\
& \text {. The effect of weight at mating تأثير وزن العنزة عند التلقيح عن : }
\end{aligned}
$$

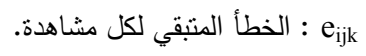

$$
\begin{aligned}
& \text { تتم رعاية القطيع الماعز في حظائر نصف مغلقة مجزةة بمسارح ومراعي ويطبق فيها نظام صحي ووقائي }
\end{aligned}
$$

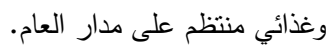

$$
\begin{aligned}
& \text { نتائج البحث والمناقثة } \\
& \text { 1- كمية الحليب ومعدل التوأمية : } \\
& \text { الجدول رقم (1) ييين نتائج القيم المتوسطات والانحراف القياسي التي تم الحصول عليها لصفات معدل } \\
& \text { التوأمية وكمية اللبن لموسم الحليب الأول لقطيع الماعز الددروس. } \\
& \text { جدول 1. يبين المتوسطات والانحراف القياسي للصفات المدروسة (معدل التوأمية وكمية الحليب لموسم } \\
& \text { ومن الجدول (1) نجد أن منوسط إنتاج الحليب لقطيع الماعز الثامي المدروس }
\end{aligned}
$$

\begin{tabular}{|c|c|c|c|c|c|}
\hline & & & & & الحلابة الأول \\
\hline & & & & أقل قيمة & أعلى قيمة \\
\hline مصادر التباين & العدد الع & المتوسط & الانحراف القياسي & للصفات & للصفات \\
\hline Veriable & $(\mathrm{N})$ & Mean & Std. Dev. & المدروسة & المدروسة \\
\hline & & & & Minimum & Maximum \\
\hline (T1) معدل التوأمية & 119 & 1.345 & 0.5115 & 1.000 & 3.000 \\
\hline كمية الحليب My1 & 119 & 276.717 & 116.905 & 115.000 & 717.000 \\
\hline
\end{tabular}

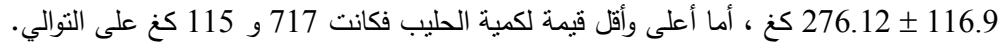

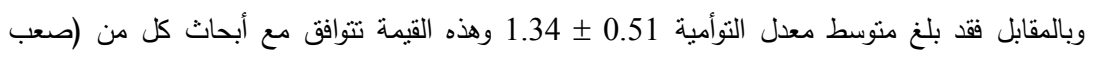

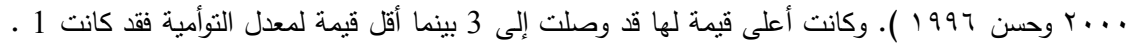

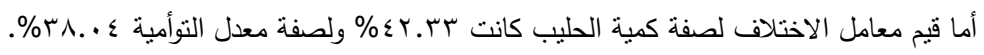




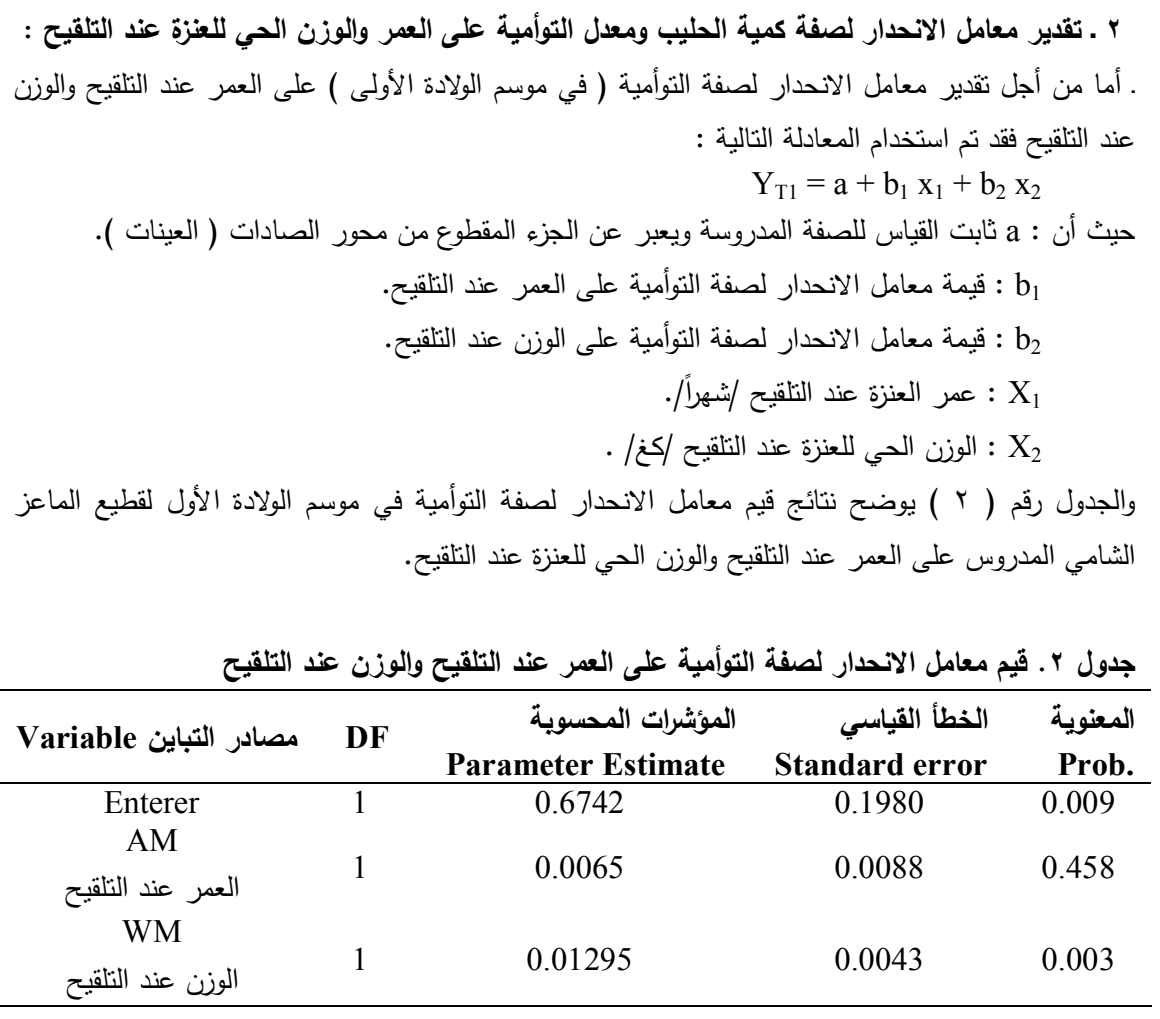

وقد أظهرت التحليلات نجد أن قيمة معامل الانحدار لصفة التوأمية على العمر عند التلقيح كانت 0.01 أي أنه كلما زاد العمر بمقدار شهر زادت التوأمية بمقدار 0.01 وكانت قيمة معامل الانحدار معنوية عند مستوى ( P 0.05 (

بينما كانت معامل الانحدار لصفة التوأمية على الوزن الحي عند التلقيح 0.01 أي كلما زاد الوزن الحي

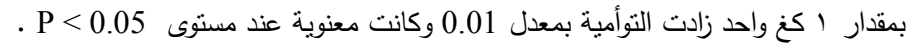

وأما الجدول رقم (r) فيبين نتائج التحليل الإحصائي لقيم معامل الانحدار لصفة كمية الحليب في موسم الحلابة الأول لقطيع الماعز الثنامي على العمر عند التلقيح والوزن الحي عند التلقيح. تبين من الجدول رقم ( r ) أن قيمة معامل الانحدار لكمية الحليب على العمر عند التلقيح كانت 11.26 وتفسير ذلك أنه كلما زاد العمر بمقدار شهر زادت كمية الحليب بمقدار 11.26 كغ. وكانت القيمة معنوية عند

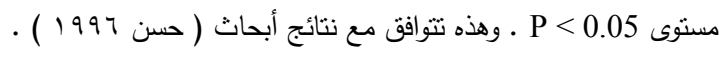
أما قيمة معامل الاتحدار لكمية الحليب على الوزن الحي عند التلقيح وكانت سالبة إذ بلغت 2.4- أبي كلما زاد الوزن الحي بمقدار / كغ واحد انخفضت كمية الحليب بمقدار 2.4 كغ وكانت ذات معنوية عالية عند مستوى P 0.01 


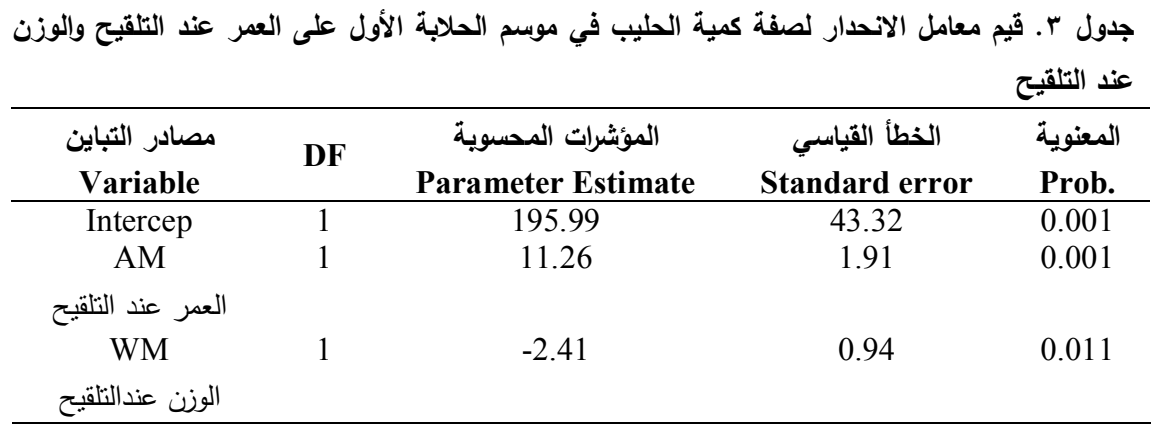

r ـ تقاير تغير متوسط إنتاج الحليب ومعدل التوأمية للموسم الأول خلال سنوات الدراسة: ويظهر الجدول رقم (ع) المتوسطات الأقل مربعات والخطأ القياسي لصفة كمية الحليب خلا سلوس سنوات الدراسة ولموسم الحلابة الأول لقطيع الماعز الثامي.

جدول ؛. يبين المتوسطات الأقل مربعات والخطأ القياسي لصفة كمية الحليب لموسم الحلابة الأول في

\begin{tabular}{|c|c|c|c|}
\hline \multirow{3}{*}{ سنوات الدراسة } & \multicolumn{3}{|c|}{ الماعز الثامي خلال سنوات الدراسة } \\
\hline & No & المتوسطات الأقل مريعات & الخطأ القياسي لصفة \\
\hline & العدد No. & لكمية الحليب + EST & SEية الحليب SE \\
\hline 1999 & 32 & 378.3 & 25.9 \\
\hline 2000 & 24 & 331.1 & 21.4 \\
\hline 2001 & 65 & 197.1 & 17.1 \\
\hline
\end{tabular}

يتضح من الجدول رقم ( ؛ ) أن منوسط إنتاج الحليب في عام 1999 كانت أكبر حيث بلغت 378 ( 199

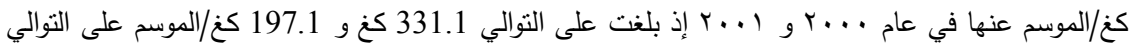
• ويعود ذلك إلى اختلاف ظروف الرعاية والتغذية بالمحطة. والتلقيح المبكر للعنزات الثامية في هذا العام.

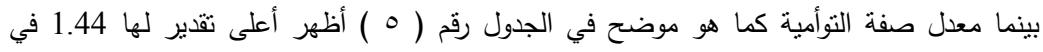

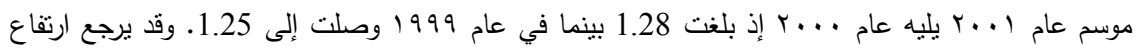

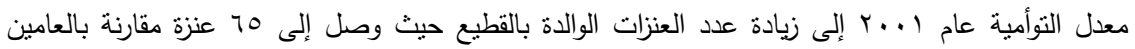




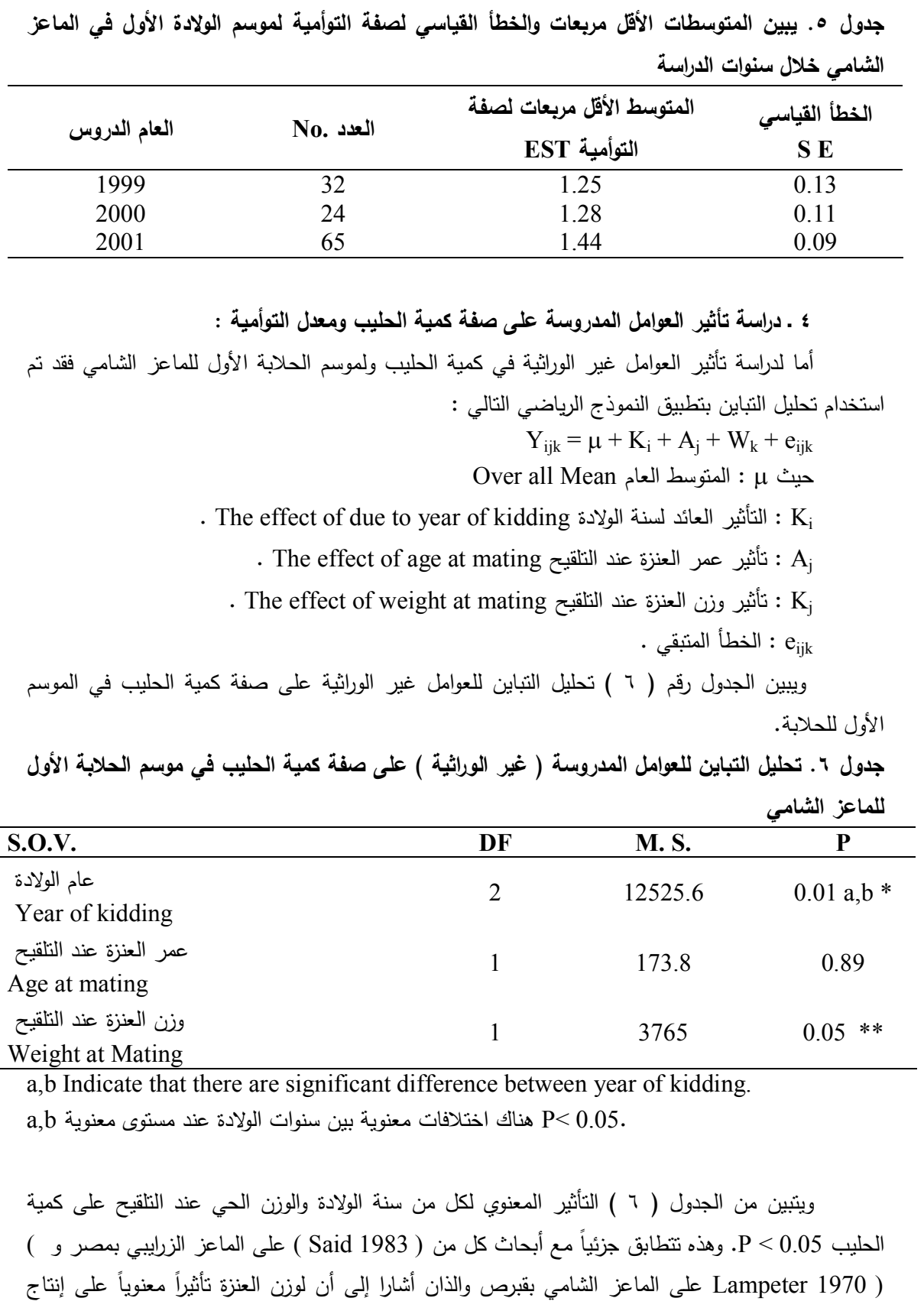




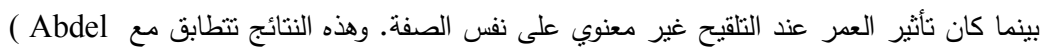

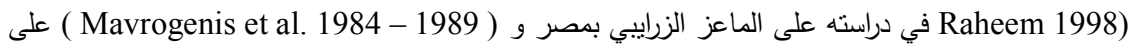

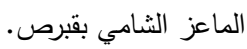
أما الجدول رقم ( V ) فيبين تحليل التباين للعوامل غير الوراثية على صفة التوأمية في موسم الولادة الأول في الماعز الثامي.

جدول v. تحليل التباين لتأثير العوامل المدروسة ( غير الوراثية ) على صفة معدل التوأمية في موسم الولادة

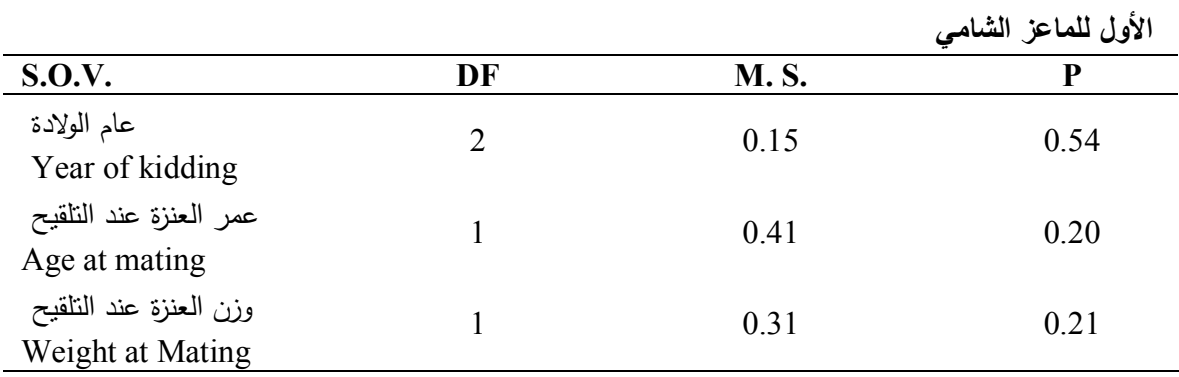

يتبين من الجدول رقم ( V ) أن ثأثير العوامل الددروسة سنة الولادة ، عمر العنزة ووزن العنزة عند التلقيح على صفة التوأمية كان غير معنوياً .

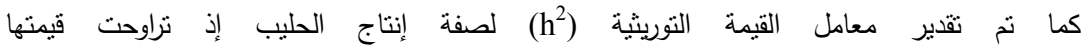

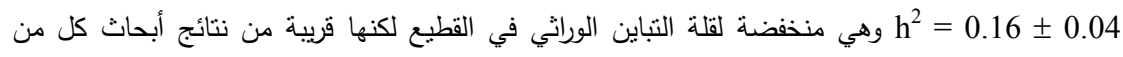

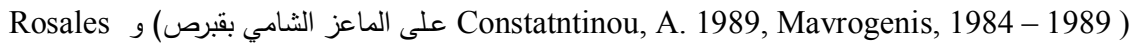
Alday, J., 1985 ( على الماعز في اسبانيا).

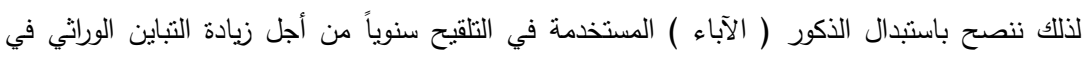

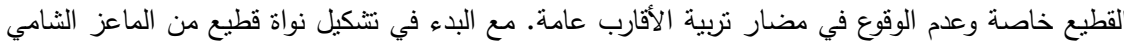

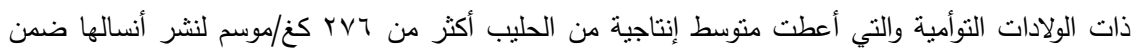

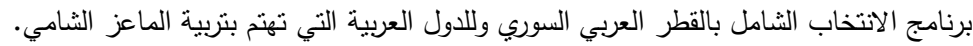
ويمكن تلخيص أهم الاستنتاجات والتوصيات فيم يلي:

1 ـ تفوق الماعز الثامي بإنتاجية جيدة من الحليب لموسم الحلابة الأول إذ بلغ بالمتوسط 116.9 م 1276.2

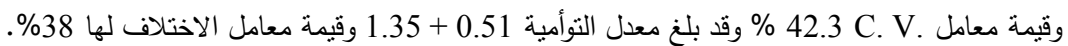

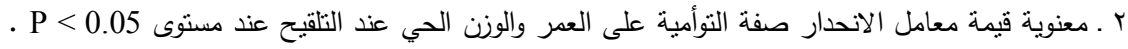

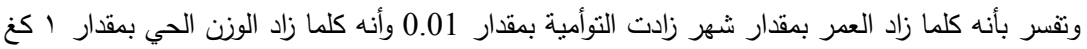

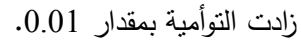
r ـ وجد أن قيمة معامل انحدار لكمية الحليب على العمر عند التلقيح 11.26 أي أنه كلما زاد العمر بمقدار شهر زادت كمية الحليب 11.26 كغ وكانت ذات معنوية عالية عند مستوى 


$$
\begin{aligned}
& \text { ع ـ قيمة معامل انحدار كمية الحليب على الوزن التلقيح كانت سالبة 2.4- أي أنه كلما زاد الوزن الحي بمقدار }
\end{aligned}
$$

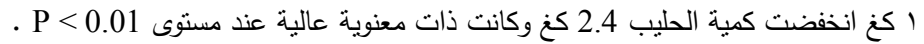

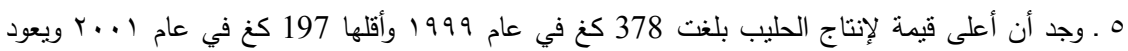

$$
\begin{aligned}
& \text { ذللك لاختلاف ظروف الرعاية والتغذية بالمحطة والتلقيح المبكر للعنزات في هذا العام. }
\end{aligned}
$$

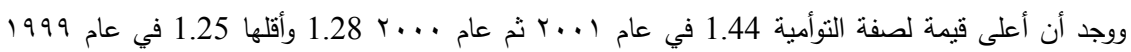

$$
\begin{aligned}
& \text { وهذا يرجع لزيادة عدد العنزات الوالدة بالقطيع مقارنة بالعامين السابقين. }
\end{aligned}
$$

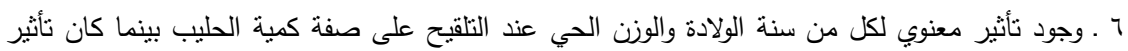

$$
\begin{aligned}
& \text { العمر عند التلقيح غير معنوياً على نفس الصفية. }
\end{aligned}
$$

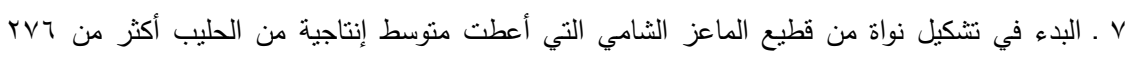

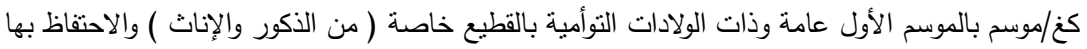

$$
\begin{aligned}
& \text { لاستخدامها كآباء ممتازة في التربية اللاحقة. }
\end{aligned}
$$

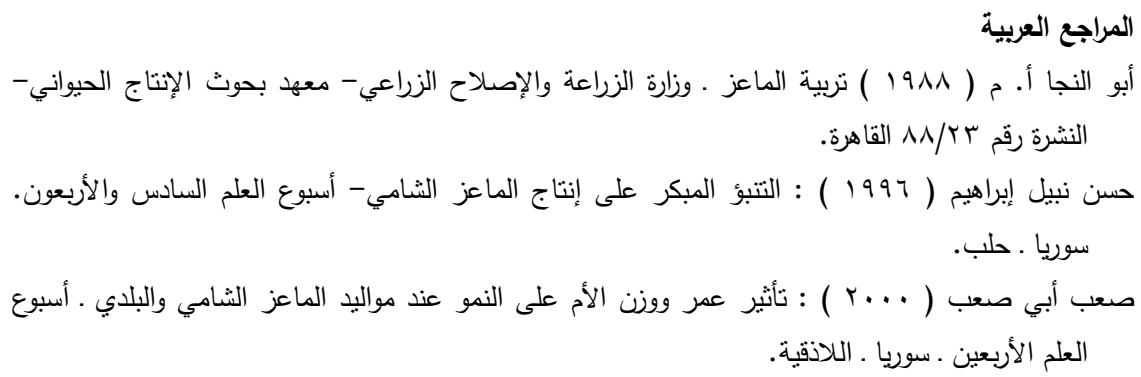

المراجع الأجنبية

Abdel-Moneim, A. Y., 1986. Studies on milk yield of Egyptain Nubian Goats. M.Sc. Thesis, Fac. Agic. Cairo University. Giza, Egypt.

Abdel Raheem, A. A., 1998. Genetic study on Zaraibi goats. ph.D. Thesis., Faculty of Agriculture. Ain. Shamc Univ. Egypt. Pp. 70

Constantinou, A., 1989. Genetic and environmental relationships of body weight, milk yield and litter size in Damascus goats. Small Eamin. Res, 2:163-174.

Devendra, C. and M. Burns, 1983 Goat production in the tropics-Commonwealth Agricultural Bureaux, Farnhom Royal. Bucks, Rngland. U.K.

Devendra, C. and K. Nozawa, 1976. Goats in south east Asia-Their stauts and production. Tierzuerhung and Zuchthugsbiologie 93, 101-120.

El-Gallad, T.T., E.A. Gihad, S. M. Allam and T.M. Bedawy, 1988. Effect of energy intake and roughage ratio on the lactation of Egyptian, Nubian (Zaraibi) goats, Small Rumin Res, 1 (4): 327-331.

FAO, 1994. Production year book. VI. Livestock numbers and products, Vol. 48, 1994, Roma, 1995.

FAO, 2002. Range-dependent Small ruminant production systems in the new East Region, Cairo - Egypt. 
Mason, I.L., 1981. Z. Wild Goats and their Domestication, Cited by Gall, C. led. Goat Production, pp. 35 - 33 Academic press, London.

Mabrouk M. M. S., A-F.M. El-Erian M. M. Tohamy and Y. A. A. El-Dweny, 1997. Milk production of Zarabi and Alpine Goats, Assiut of-Agri, Sci: 18 (2):231- 252.

Mavrogenis A.P., A. Constantntinou and A. Louca, 1984 Environmental and genetic causes of variation in production traits of Damascus goats, 2. Goat Productivity. Anim. Prod. 38:99-104.

Mavrogenis, A. P., C. Papachris to forou, L. Lysandrides and Rousnias, 1989. Environimental and genetic effects on udder charactristics and milk production in Damascus goats. Small Rumin. Res, 2:333-343.

Rosales Aday J., 1985. Heritability of some production characters in goats, Veterinaria Mexico, 15:163-165, Animal Breed. Abstr. 68 ( 1985).

Said, M.M., 1983. Studies on some production traits of Egyptian goats, M. Sc.Tesase Fac, Agri. El-Ezhar Univ. Cario, Egypt.

Said, M. M., 1983. A study on production of Egyptian goat. M. Sc. Thesis Fac. Agric. Zagazig Univ. Egypt. Pp. 117.

SAS, Institute, 1994. SAS / Stat User's statistical Ver, 6.04 Fourth edition SAS Inc.

Wilson, R.T., 1991. Small Ruminant production and small Ruminant Genetic Resoures in Tropical Africa. FAO. Animal Production and Health paper 88, Roma 1991. 


\title{
A STUDY OF SOME FACTORS AFFECTING FIRST LACTATION PERFORMANCE AND KIDDING RATE OF SHAMI GOAT IN SYRIA
}

\author{
N. Khalouf ${ }^{1}$ and Mona Abd Al Zaher ${ }^{2}$ \\ 1- Department of Animal Production, Faculty of Agriculture, University of Aleppo- \\ Syria, 2- Department of Sheep and Goat, Animal Production Research Institute, \\ Agriculture Reasearch Center in Egypt
}

\section{SUMMARY}

A total of 119 records collected at Homaemeh Station at the research center of Agriculutre in North of Syria from 1999 to 2001 were used to study some factors affecting first lactation performance and kidding rate in Shami goats.

Data collected were analyzed by computer using SAS program.

Average milk yield was $276 \pm 116 \mathrm{~kg}$ and cofficient of variation was $42 \%$. Average kidding rate was $1.35 \pm 0.51$ and the cofficient of variation was $38 \%$. The higherst milk yield was $378.3 \pm 26 \mathrm{~kg}$. in 1999 while the lowest was $197 \pm 21.4 \mathrm{~kg}$. in 2001 . It was found that the kidding rate was $1.44 \pm 0.09$ in 2001 while the lowest one was 1.25 \pm 0.13 in 1999 that was related to the increased number of animals in last 2 years. Cofficient of regretion of kidding rate on age and weight at mating was significant $(P<0.05)$ and highly significant $(P<0.01)$ for cofficient regretion of milk yield on age and live body weight of goats. Most traits were significantly affected at milk yield $(P<0.05)$.

Keyword : Shami goat, first lactation, milk yield, kidding rate, weight at mating, age at mating 